\title{
Meaning and Meaning Making in Arabic: Moving from Semantics to Pragmatics to Ka:rmatics
}

Muhammed Salim

Ph.D. Research Scholar

Department of Linguistics

Aligarh Muslim University

Aligarh, India.

\section{Chilukuri Bhuvaneswar}

Founder President

Karmik Linguistic and Literary Association (KLLAS)

Hyderabad, India

alsalim2014@gmail.com

\begin{abstract}
Ka:rmik Linguistic theory is one of the most revolutionary theories in linguistics which aims to describe language from a causal perspective of WHY giving rise to WHAT through HOW: "As you are, so you think; as you think, so you speak (or act)" (Bhuvaneswar). In an adapted form, it can be modified as: As you are, so you think; as you think, so you mean. In his extension of semantics to ka:rmatics in dealing with proverb-meaning, Bhuvaneswar (2012) has shown a new dimension of meaning and meaning-making, namely, the causal dimension of creation, change, and transformation of meaning in language. According to Bhuvaneswar, if semantics deals with sentence meaning and pragmatics with utterance meaning, ka:rmatics (i.e., experiential pragmatics) explores experiential meaning via dispositional meaning of
\end{abstract}


contextual meaning (pragmatics) of sentential meaning (semantics). What this amounts to is a causal understanding of meaning as it is created, changed, and transformed as languages are evolved and developed: Language is as it is (i.e., lingual meaning is as it is) because of what it is (dispositionally) intended to do (i.e., to mean) what it does (i.e., means).

In this paper, an attempt has been made by selecting two sentences used in real life Yemeni Arabic to show how meaning is derived. In the process, it will be shown how semantics becomes pragmatics and pragmatics becomes ka:rmatics.

Keywords: semantics, pragmatics, ka:rmatics, ka:rmik linguistic theory, Yemeni Arabic, ka:rmik, proverbial meaning

\section{Introduction}

In the history of semantics, meaning has been studied from various aspects both in the east and the west. In the west, truth, use, and ideation (see the Wikipedia article on Meaning) are taken as the basis for studying meaning and in the east, meaning has been studied extensively at the word and sentence levels and such ideas as abhida (primary meaning of a word), sphota, apoha, anvitabhidana, abhihitanvaya, and vyanjana are proposed (see Kunjunni Raja 1963 for details). However, one important aspect which is disposition has been overlooked or not given enough treatment. Such a perspective will give rise to a new dimension in meaning-making and leads to an entirely new branch called Ka:rmatics (experiential pragmatics) as proposed by Bhuvaneswar (2009). In this paper, an attempt has been made to motivate meaning-making in a few recent neologisms from a ka:rmatic perspective.

\subsection{Aims and Objectives}


The aim of this paper is to study how new meanings are created and the objective of this paper is to investigate how meaning is made in a few recently developed new meanings in Yemeni Arabic and motivate it in the ka:rmatic framework of KLT.

\section{2. Materials and Methods}

The data investigated is collected from real Yemeni daily conversation. Each one of the examples given in section three has acquired new meaning. By applying the standard KLT procedure, the process will be motivated in Section III.

\section{3. Research Question}

How are sentential meanings created in Yemeni Colloquial Arabic?

\section{4. Hypothesis}

It is hypothesized that meaning is the product of Dispositional Creativity and Social Cognition by Variable Dispositional Cognition (PVDSC) of the Yemeni community in their creation of the new meanings for the collected samples.

\section{4. Scope and Limitation}

The scope of this is the few new emerging meanings that have gained wide publicity among Yemenis in 2017 and 2018 and is limited to such emergent meanings only.

\section{5. Significance of the Study}

The significance is it is the first time that Ka:rmatics is applied to Yemeni Arabic sentential meaning-making.

\section{6. Definition of Technical Terms}


1. Meaning: According to Bhuvaneswar, meaning is "(dispositionally) differentiated awareness of this and that to be so and so in such and such manner". It implies a two-fold distinction of form-oriented universe and name-oriented universe being united in their awareness as meaning of the former as the latter and vice versa in the case of language. To explain further, a material object, say, the object represented by the name 'tree' in English is a part of the form-oriented universe while the word 'tree' representing the object 'tree' is a part of the name-oriented universe. The underlying awareness of the object 'tree' as the name 'tree' and vice versa is what constitutes meaning - it is dispositionally differentiated, identified and qualified and then unified in its totality. In its immediate level, it is functional in identifying, qualifying and substantiating objects, action, and the relationship between them - in other words constructing actional reality; at its intermediate level, it is functional in choosing, sequencing by deliberation and networking actional reality - in other words constructing dispositional reality; at its higher level, it is functional in experiencing dispositional reality as actional reality, existential reality as living reality and living reality as ka:rmik reality. To sum up, meaning is a product of disposition and consciousness of the phenomenal world as qualified and differentiated awareness in its variety-range-depth.

2-3. Superimposition (adhya:sa) and vivartam (apparent transformation) :

According to S'ri: A:di S'amkara Bhagavatpu:jyapa:da:h, Adhya:so: na:ma atasminstadbuddhirityavo:cham 'We have said that adhya:sa is the cognition of something as some other thing'; or more technically, smritirupah (by memory) paratra (somewhere) poorvadrshta (previously seen) : (a)vabhasah (glowing or cognition) 'Adhya:sa is the cognition of something previously seen by memory on another thing elsewhere'. This is with reference to the explanation of the effect, jagath (universe or creation), as an adhya:sa - the technique - on Brahman (God) owing to avidya (ignorance), the cause. Brahman is seen as 
the universe like rajju sarpa bhranthi (illusion of a snake on a rope) - here, a snake whose knowledge occurs from memory is seen on a rope (some other thing) by its adhya:sa (superimposition) through ignorance.

Vivarta (as the effect) is 'the apparent transformation (transfiguration) of one thing as another'. The seeing of a snake on a rope is not due to real transformation like milk into curd but due to an illusion; the moment a torch light is focussed on the apparent-snake, it vanishes into the rope. These two concepts are observed in the creation of new meaning and meaningmaking.

\section{Literature Review}

In the western tradition, there are many theories of meaning which can be divided on the basis of truth, usage and idea(tion). Under truth and meaning, we have many substantive and associated theories. According to Wikipedia (2019), within substantive theories of meaning, we five important theories dealing with: Correspondence; Coherence; Constructivism; Consensus; Pragmatics. Under associated theories, Gottlob Frege, Bertrand Russell, Saul Kripke contributed prominently. Under usage based theories, Ludwig Wittgenstein, J. L. Austin, Peter Strawson, Paul Grice, Inferential Role Semantics are important. Within Idea Theory of Meaning, there are stronger and weaker versions.

In the Bha:rati:ya sa:mprada:ya (Indian tradition), intense discussion on meaning was carried out. The ideas of khandapaksham (analytical method) and akhandapaksham (gestalt theory), abhidha (primary word meaning), sphota (the linguistic sign), aka:nksha, sannidhi, yo:gyata, and ta:tparyajna:na (as conditions of knowing the meaning of a sentence), anvita:bhidha:na and abhihita:nvaya for the comprehension of the meaning of a sentence, lakshana (metaphor), vyanjana (suggestion) are contributed to Indian semantics. For a 
detailed discussion of these aspects - not done here owing to word-limit constraints - see "Meaning", Wikipedia for the western theories and Kunjunni Raja (1963) for Indian theories. 2. 1. Research Gap: In spite of this great contribution to semantics, the emphasis is on decoding meaning from words and sentences and not on motivating the creation of new meanings in them through defined linguistic processes.

2. 2. Proposed Solution: The use of the concepts, principles, and processes outlined in Ka:rmatics can provide a solution to overcome this gap. It is explained in the next section.

\section{Meaning-making in Yemeni Arabic: A Ka:rmatic Approach in KLT}

The data collected has been examined based on the five stages of the Standard KLT procedure: 1. Data Collection; 2. Patterning and Structuring; 3. Concepts and Principles; 4. Systemic Network of Choices; and 5. Ka:rmik Linguistic Motivation.

\section{1. Data Collection}

Two samples from Yemeni Arabic conversation where new meanings have been created are collected for ka:rmatic analysis:

(1) Wazzanak (وَزَّزَكَك()

Weight-pst- you

Referential meaning: "he weighted you."

Meaning created by Adhya:sam and Vivartam: "He deceived you".

In standard Arabic, "Wazzanak" (وَزََّنك (1) in (1) means "He weighted you." However, it has acquired its new meaning in Aligarh, India. This new meaning was introduced by a Yemeni person, who shipped some luggage to Bangalore, India but unfortunately he was overcharged. He paid for extra $60 \mathrm{~kg}$. Possibly, he realized later that his exact weight has been added to weight of the luggage. Therefore, instead of just paying for shipping the 
luggage, he himself has been weighed and he has to give extra money. He was deceived and since then the new meaning has been practiced, popularized, and circulated among Yemenis in Aligarh (see ICCCSA in KLT). Here is another real life example:

(2) Pkal yakul tuffah

Ate-3sm/ eat-3sm apples

Referential meaning: "he ate apple."

Meaning created by Adhya:sam and Vivartam: "He died/was killed".

/Pkal tuffah/ 'ate apple' gained a new meaning by extension on 26 Jan 2017 from a Yemeni flash clip. That dialogue in the clip is translated in (3).

(3) A: hey, master. Abu alhussain (saleh Muhumed) has been killed !

$$
\text { (يا سيدي:ابو الحسين صالح محمد قُتِل) ( }
$$

B: where (أين)

A: in Mydi port (في ميدي)

B: in the pardise, eating apples ! [A exits]

C: oh, master, abu Raad Muhmmmed Yahya has been killed in Taiz.

$$
\text { (يا سيدي:ابو ر عد محمد يحي قُقِلَ في تعز ) }
$$

B: in the paradise, eating apples! (في الجنه ياكُل تُفّاح) [C exits]

D:Oh, master, they said that Abu Ali martyred in Fortha frontline.

$$
\text { (يا سيدي: قالو ا ابو علي استشهد في جبهة نهم) }
$$

B: in the paradise, eating apples! (في الجنه ياكُل تُفّاح) [D exits]

A:Oh, master, Muhammed died

$$
\text { (يا سيدي:محمد توفى) }
$$

B: in the paradise, eating apples! (في الجنه ياكُل ثُفّاح)

A: Mahammed, Muhammed(محمد محمد) 
B: Mahammed who?(محمد من) )

A: Mah...Muh.... Muhammed, your son. (مح........محمد ابنك)

B: What, Mahammed? Who took him there? Why did he go? [End of the Clip]

$$
\text { (ايش.محمد؟من شله الى هناك؟ ليش سار؟) }
$$

The dialogue above shows that there is a conversation between $\mathrm{B}$ on the one hand and A, C, D on the other. B plays the role of a military leader throughout the dialogue. Notice that whenever B was told that someone has been killed or martyred, he (B) does not care at all. He just thinks being martyred or killed is a bliss or a privilege that qualifies the killed one to eat apple in the paradise. Religiously speaking, it is believed in Islam that martyr does not die at all. This is indicated in "( $3: 169)$ think not of those slain in the way of Allah as dead. ${ }^{*} 120$ Indeed they are living, and with their Lord they have their sustenance" (al-baqarah, Holy Quran). Being alive, they can get “ (20)the fruit they prefer"(al-waqeSah, Holy Quran).Therefore, it can be said that the meaning of eating apple-apple being one type of fruit- is extended to mean "killed".

\section{2. Patterning and Structuring}

At the formal syntactic level, the sentences in (1) and (2) are of the type VSO word order (see Ryding 2005 for a detailed discussion of the structure of the verb's PNG and tense features). Our main interest here is not in the syntax of the sentences but in the process of how they have been used by extension of the referential meaning to give a new meaning. From the analysis of the data, we observe that in (1), an actual social event that occurred became the basis for the creation of a new meaning; and in (2), so did the religious Koranic knowledge. Hence, two patterns are observed: Adhya:sa (superimposition) and Vivartam (apparent transformation) of: 1. Social Praxis; and 2. Previous Knowledge to Create New Meanings. 


\section{3. Concepts and Principles}

When we causally investigate the creation of new meanings in (1) and (2), we find out that the process applies the following concepts and principles:

\section{3. 1. Concepts: Adhya:sam and Vivartam}

In the first example, wazzanak 'He weighted you', we find a cognitive process of adhya:sa (superimposition). Here, there are five issues:

(1) weighing of the luggage along with the person - Real Life Incident; inference and abstraction of the meaning of 'getting cheated' from (1)

(2) ru:pa:dhya:sam (form-superimposition) of (1) on some other similar incident - Metaphoric Cognition of an event (practice);

(3) vivartam of (1) into the similar incident as (3) - Apparent Form-Transformation;

(4) The jna:na:dhya:sam of the meaning of 'getting cheated' from (1) on (2) as (4) - Metaphoric Cognition of Meaning;

(5) its vivartam in a contextual use - Apparent Knowledge Transformation

\section{3. 2. Principles: Standard Pentads (SP)}

The Major Standard Pentad Three (MSP 3) for Creation of Lingual Action (CLA): Dispositional Creativity (P DCr); Exploration of Variables (P EV); Computation $(P D C)$; Substantiation (PoS) are applied to motivate the creation of the new meanings and the Principle of Disposition $(P o D)$ is used to motivate the choice of the new meaning. Finally, the Principle of Karmaphalabho:gam $(P o K P B)$ is applied to motivate the creation of the new meaning, its use, and its acceptance as a norm. A brief discussion of these principles is made in 3. 4. as follows. 
3. 4. Dispositional, Systemic Choice Network

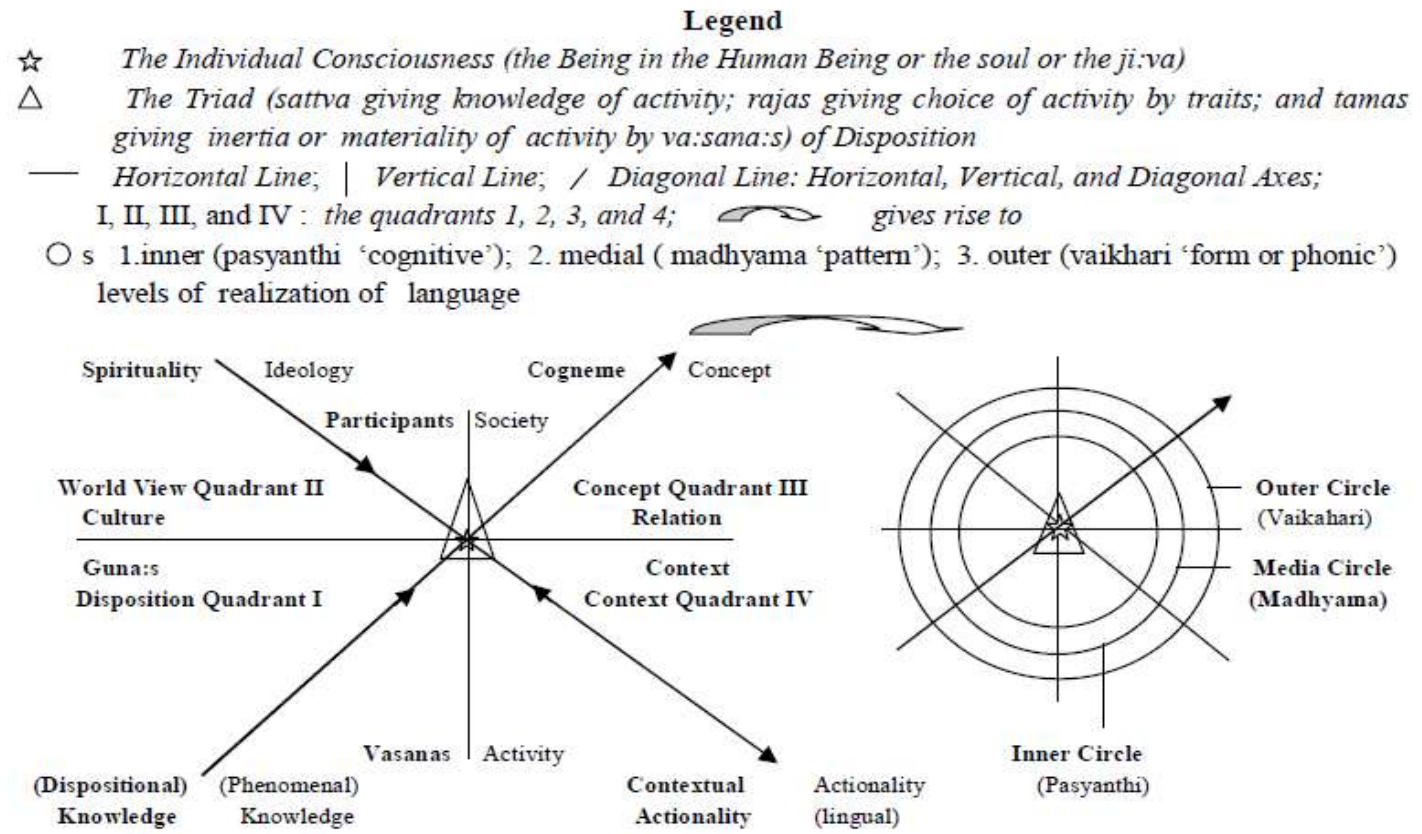

Network 1: Quadrant Graph of Cognitive Lingual Action and Its Realization

When the person who experienced the event of his being weighed along with his luggage, that event shown in WV Quadrant 2 left an impression in his mind as shown in the centre of the graph in a triangle D-q-C in the Network 1. By the power of analyticity from the Disposition Quadrant 1, that event gets interpreted and it is inferred that he was cheated. 'That P: That he was cheated by adding his weight also to the luggage' is cognized in the Cogneme Quadrant 3. Now, 'That $\mathrm{P}$ ' became a special impression, gained salience and created a dispositional functional pressure (DFP) which triggered an impulsion to semiotically represent that meaning in language. Here, P DCr. and P EV come into play.

P DCr is: "Dispositional creativity is a flash of a new insight impelled by DFP by a creative choice of the variables in US A as reflected in the US LA through US L individualized by svabha:vam (Bhuvaneswar). Causally, it can be sa:ttvik-ra:jasik-ta:masik leading to novelty by luminosity-change by expansion and variety-change by contraction and monotony according to the influence of the three guNa:s in svabha:vam; it can also ra:jasik- 
ta:masik or vice-versa giving rise to transformation. In process, it can create-extenddelete/transform a variable; and as a product, it can be a neologism, an extension, a contraction (e.g., abbreviation, acronomy) or transformation (say ra:jasik-ta:masik conversion in word-formation or ta:masik-ra:jasik conversion by extension in meaning). Owing to the DFP arising in the speaker to use language creatively and his va:sanas (internalized habits) of adhya:sam and vivartam, he was impelled by his guNa:s (traits) for variety and novelty; then, he reflected on his knowledge of the social practise 'of getting himself weighed along with the luggage' shown by R1-R2 in the Network $2 \mathrm{~b}$; as
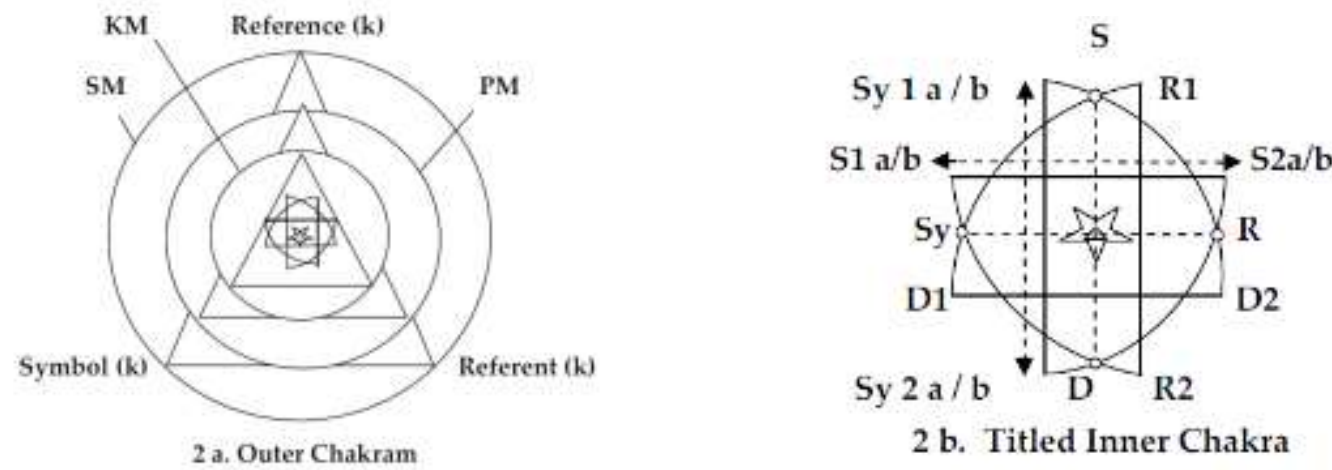

2 b. Titled Inner Chakra

Legend: $\quad$ SM semantic meaning; PM pragmatic meaning; KM ka:rmatic meaning $\mathrm{S} 1 \mathrm{a} / \mathrm{b}$-S2 a/b Sense Bar; D1-D2 Disposition Bar; R1-R2 Referent Bar Sy 1a/b - Sy 2a/b Symbol Bar; S, D, R, Sy Sense, Disposition, Symbol, Referent produced by intersections of the concerned bars; $\stackrel{M}{ }$ C-q-D (Consciousness-qualified-Disposition)

Network 2: Emergence of Meaning by Mutual Superimposition Network

he did so in a context, the flash of a new insight dawned on him to use 'wajanak' indicated by Sy1 1b-Sy2 $2 b$ to give the new meaning 'cheated' as indicated by S1 b-S2 b instead of the referential meaning indicated by $\mathrm{S} 1$ a-S2 a for the sentence Sy $1 b-S y 2 b$. The difference between the sentence meaning (SM), pragmatic meaning, and ka:rmatic meaning lies in the 
use of the sentence literally - contextually - experientially as shown in 3a. Language in isolation (semantics) becomes language in use (pragmatics) becomes language in experience (experiential pragmatics or semantics as pragmatics as ka:rmatics). In ka:rmatics, there is provision for individual-collective variation in meaning. For example, wazzanak can be understood as simply 'weighted you' or 'cheated you' depending upon the knowledge of the user of the social practice ; ni:LLu po:sukundi means 'she bathed' in the Circar Telugu but 'she took a bath on the $11^{\text {th }}$ day after delivery' in Telangana.

P EV is: "Exploration of Variables $(P E V)$ is dispositional in its VRD of finding variables and their computation". It has three sub-principles which are the Principle of Productive Extension of a Variable (P Pr EV) in which the existing variable is productively The final systemic choice network is captured below. 


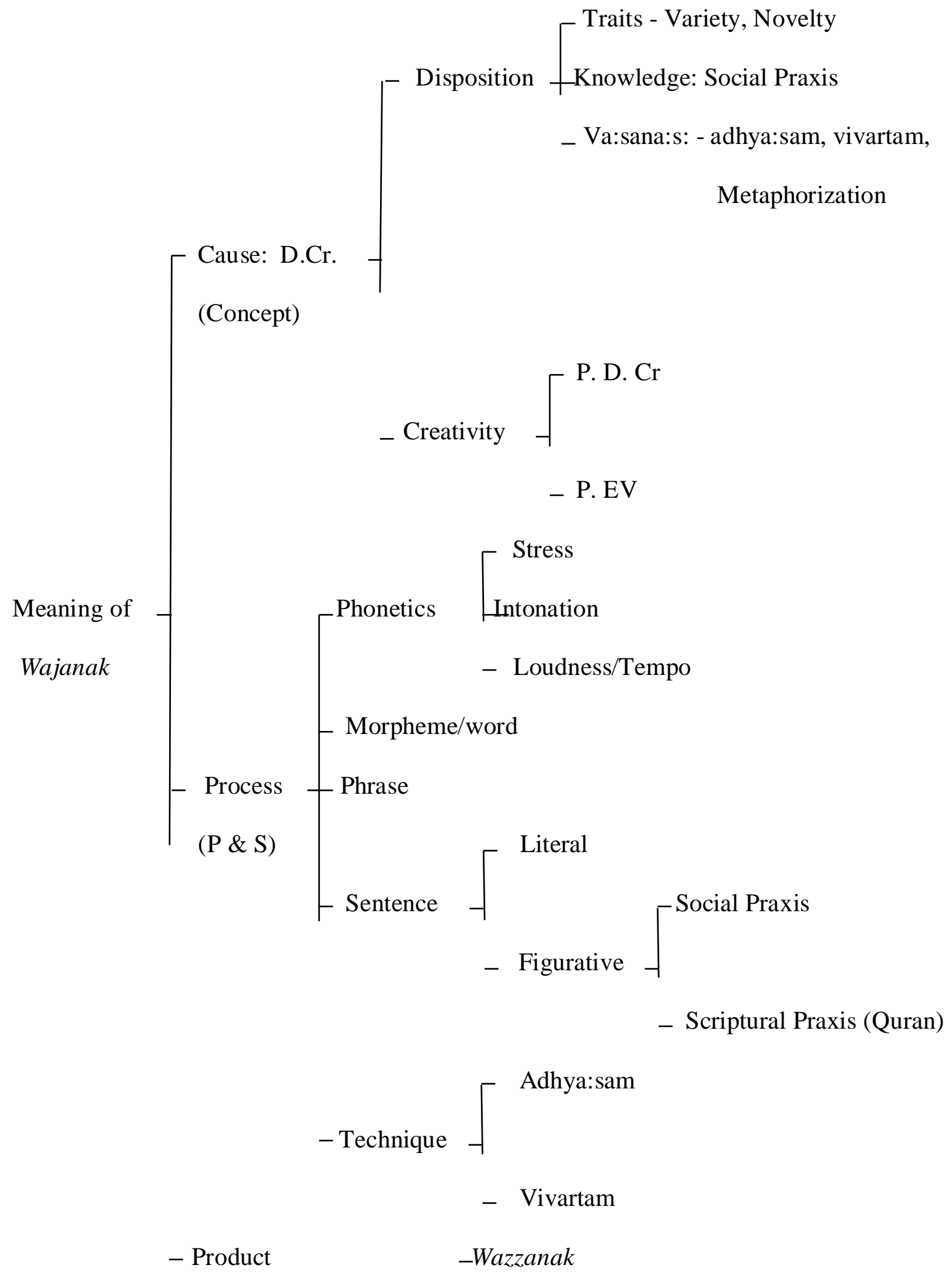

(Substantiation) Network 3: Wazzanak Meaning 
extended (e.g., pool-swimming-pool); Principle of Deletion or Transformation of a Variable (P D.oV or $\mathrm{P}$ ToV) in which deletion or transformation of a variable $(\mathrm{D}$ oV or $\mathrm{T} \mathrm{oV})$ takes place (e.g., narrowing in meaning or abbreviation in Word-formation); and the Principle of Creation of a New Variable (P CNV) in which a new word/phrase/sentence with a new meaning is created; sometimes, it can involve $\mathrm{P}$ PrEV/P DoVor P ToV. By doing EV to represent this meaning, the speaker has hit upon the very wording of the event wazzanak 'He weighted you' as a sentence with 'wazzan' by its dispositional choice by the P ToV. He did not choose the other options such as: "Zād Galyā"( زاد عليّ-played a trick on me), "xadaSani"

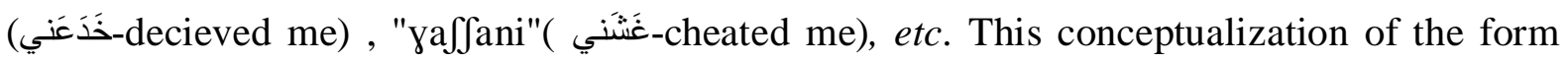
together with the new ka:rmatic meaning ' $(\mathrm{He})$ cheated you' is cognized as the cogneme in the Cogneme Quadrant 3 where the semantic meaning of wajanak is transformed ta:masikra:jasikally into the ka:rmatic meaning and finally realized in the context of its dispositional use in the Context Quadrant 4 in the Network 1 via its materialization through pasyanti, madhyama, and vaikhari as shown in the next part (see Bhuvaneswar 2019 for a detailed discussion of these terms). The transformation of semantic-pragmatic-ka:rmatic meaning is shown in the Network $2 \mathrm{a}$ in three layers along with the cognition of it in the centre.

\section{Ka:rmik Linguistic Motivation}

One important reason why the new meaning is created is novelty and fun. Another reason is the functional necessity to express such meanings which do not have equivalents. Since such meanings are relevant in current social praxis, such a meaning is accepted in interpersonal communication (IPC) between one individual (I) and another in the Yemeni society in Aligarh Muslim University (AMU) where this usage is initiated and continued. 


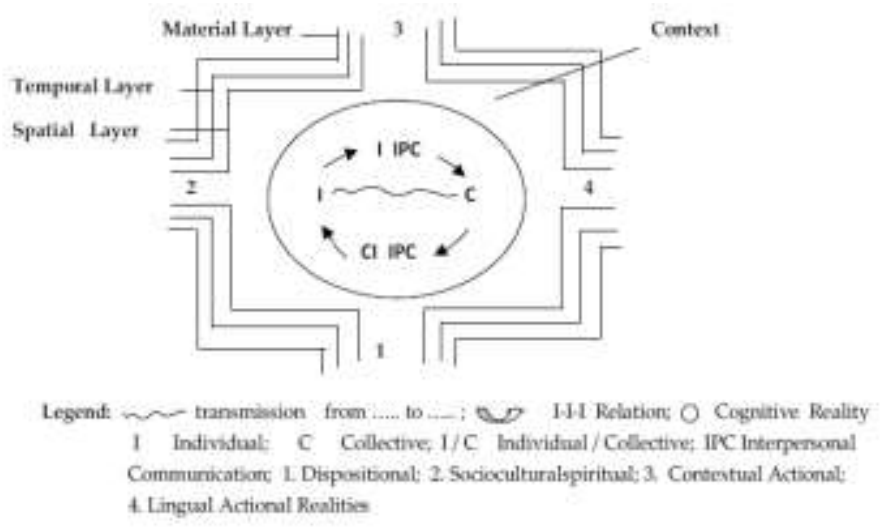

Network 3. Ka:rmik (Dispositional) Transmission of Language by ICCCSA

As it has gained currency, it became established at the AMU Collective (C) level and nowadays it is commonly used in the Collective - Individual IPC (CI IPC) in the Spatiotemporal material context for the construction of ka:rmik reality via lingual actionalcontextuaal actional-SCS-STM-Cognitive realities as shown in the following network (for more details on ICCCSA, see Bhuvaneswar 2019).

One such example is given below where it is used by an AMU student as a comment in the context of a taxi driver charging more than the normal price of Rs 10 per kilometre:

(4) a. al-sawaq axath xamsata Sashr rubeeah lil-kiloo

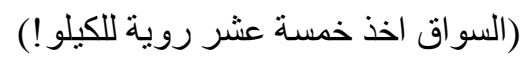

"The driver took 15 rupees for each kilo (meter)."

b. wazzan-kum (وَزّْزَكَم)

"He deceived you (pl.)."

An important observation regarding this usage is its tendency to become a proverbial expression in future if it gains more currency and popularity and eventually it may end up as an idiom.

In the case of the example (2), a similar type of analysis can be conducted. The only difference between (1) and (2) is in (2), the idea is derived from a knowledge of the Holy 
Quran and it is narrowed down in meaning from fruits to apples and then used as already discussed in 2. Data Collection at the beginning. It is not analyzed here for want of space.

\section{Conclusion}

This study concludes that meaning is a socio-cogntive concept that is dispostionally triggered, created and circulated. This theory opens new horizons for linguistic study as it moves from semantics to pragmatics to ka:rmatics. It was observed that ka:maik meaning is experiential and it is karmatics that that gives rise to new meanings. Hope this paper serves as a springboard for further research and explore the area of ka:rmatics in Yemeni Arabic which is virgin. 


\section{References}

Bhuvaneswar (2009). "CLT and KLT: A Contrastive Review”. Al Mergib Journal of English Studies, Vol. 2. Ghasar Khiar, Al Mergib Universityj

Bhuvaneswar, Chilukuri (2010). "Derivation of Referential Meaning in Proverbs I Propositional Meaning: A Ka:rmik Linguistic Approach”. Misurata Univeristy Journal of English Studies, Vol.1. Ghasar Khiar, Misurata University, June, 2010. P. 208-231.

Bhuvaneswar, Chilukuri (2013). "Derivation of Referential Meaning in Proverbs 2 Syntactic Meaning of Complex Speech Acts: A Ka:rmik Linguistic Analysis”, In:

Series «Modern Linguistic and Methodical-And Didactic Researches», Scientific Newsletter, 1 (2),Voronezh State University of Architecture and Civil Engineering, Voronezh, Russia. 17-31

Bhuvaneswar, Chilukuri (2013). "Proverbial Linguistics: Theory and Practice in the Ka:rmik Linguistic Paradigm - Creation and Development of Proverbs (Fourth Part of the Plenary Speech). (Eds.). BENAYOUN, Jean-Michel/ Kubler Natalie/ZOUOGBOj Jean-Philippe (2013). «Parémiologie. Une identité affirmée». Actes du Colloque International Parémiologie, 2011, Volume I et II. Saintes Gemme: Universitaire Saintes Gemmej Bhuvaneswar, Chilukuri (2019). "Ka:rmik Linguistic Theory and Practice: An Overview of Some Basic Concepts, Principles and Procedures for Doing Research.” Keynote Speech. International Conference on Linguistics, Literature, and Language Teaching. Greater Noida: Sharda University.

Holy Quran. Retrived from: https://quran.com/2

Kunjunni, Raja. (1963). Indian Theories of Meaning. Madras: Adyar Library and Research Centre . 
SMART MOVES JOURNAL IJELLH e-ISSN: 2582-3574 p-ISSN: 2582-4406 VOL. 8, ISSUE 11, NOVEMBER 2020

Wikipedia (2019). https: //en.wikipedia.org/wiki meaning_philosophy_of_language \#substantive_theories_of_meaning. 